\title{
Apparent paradox of neurohumoral axis inhibition after body fluid volume depletion in patients with chronic congestive heart failure and water retention
}

Maurizio D Guazzi, Piergiuseppe Agostoni, Battista Perego, Gianfranco Lauri, Alessandro Salvioni, Francesco Giraldi, Marco Matturri, Marco Guazzi, Giancarlo Marenzi

\section{Abstract}

Background-Hypovolaemia stimulates the sympathoadrenal and renin systems and water retention. It has been proposed that in congestive heart failure reduction of cardiac output and any associated decrease in blood pressure cause underfilling of the arterial compartment, which promotes and perpetuates neurohumoral activation and the retention of fluid. This study examined whether an intravascular volume deficit accounts for patterns that largely exceed the limits of a homoeostatic response, which are sometimes seen in advanced congestive heart failure.

Methods and Results-In 22 patients with congestive heart failure and water retention the body fluid mass was reduced by ultrafiltration and the neurohumoral reaction was monitored. A Diafilter, which was part of an external venous circuit was regulated to produce $\mathbf{5 0 0}$ ml/hour of ultrafiltrate (mean (SD) 3122 (1199) $\mathrm{ml}$ ) until right atrial pressure was reduced to $50 \%$ of baseline. Haemodynamic variables, plasma renin activity, noradrenaline, and aldosterone were measured before and within 48 hours of ultrafiltration. After ultrafiltration, which produced a $20 \%$ reduction of plasma volume and a moderate decrease in cardiac output and blood pressure (consistent with a diminished degree of filling of the arterial compartment), there was an obvious decrease in noradrenaline, plasma renin activity, and aldosterone. In the next 48 hours plasma volume, cardiac output, and blood pressure recovered; the neurohumoral axis was depressed; and there was a striking enhancement of water and sodium excretion with resolution of the peripheral oedema and organ congestion. The neurohumoral changes and haemodynamic changes were not related. There were significant correlations between the neurohumoral changes and increase in urinary output and sodium excretion.

Conclusions-In advanced congestive heart failure arterial underfilling was not the main mechanism for activating the neurohumoral axis and retaining fluid. Because a decrease in circulating hormones was associated with reabsorption of extravascular fluid it is likely that hypoperfusion and/or congestion of organs, such as the kidney and lung, reduce the clearance of circulating noradrenaline and help to keep plasma concentrations of renin and aldosterone raised. A positive feedback loop between fluid retention and plasma hormone concentrations may be responsible for progression of congestive heart failure.

\section{(Br Heart $\mathcal{f} 1994 ; 72: 534-539)$}

La constance du milieu intérieur est la condition d'une existence libre et indépendente.

A decrease in the volume of body fluid leads to reduced excretion of salt and water and activation of the sympatho-adrenal and reninaldosterone systems. Bleeding, ${ }^{2}$ pharmacological diuresis ${ }^{34}$ and, possibly, cardiac insufficiency ${ }^{56}$ activate this defence reaction. In heart failure retention of water and salt and neurohumoral stimulation can greatly exceed the limits of a homoeostatic response. ${ }^{7}$ To explain this, Peters coined the term "effective blood volume", 8 which was subsequently identified as the state of filling of the arterial compartment. ${ }^{4}$ According to these concepts, a reduction of the output of the heart and any decrease of blood pressure in heart failure can be regarded as an intravascular volume deficit, ${ }^{9}$ and the neurohumoral reaction would be perpetuated if the haemodynamic disorder persisted. Clinical studies of frusemide and ultrafiltration accord with this view. Acute volume depletion by intravenous frusemide or ultrafiltration, ${ }^{10-13}$ in patients with congestive cardiac failure was associated with increased systemic vascular resistance and reduced cardiac output and blood pressure (consistent with hypovolaemia) and an additional increase in plasma noradrenaline, renin, and aldosterone. ${ }^{14-19}$ However, two points should be considered: frusemide stimulates the renin system independently of volume depletion ${ }^{16}$ (the associated increase in plasma noradrenaline may be, at least in part, mediated through facilitation of the neurotransmitter release by angiotensin $\mathrm{II}^{2021}$ ) and in patients with heart failure and congestion ultrafiltration reduced rather than increased concentrations of circulating hormones. So does vascular underfilling alone account for the striking neurohumoral activation and fluid retention that occur in the more advanced stages of the disease?

This question prompted us to perform a 48 hour follow up study of patients with congestive heart failure and fluid retention who had ultrafiltration alone. 


\section{Patients and methods}

PATIENTS

We studied 22 patients with congestive heart failure admitted to the Institute of Cardiology, University of Milan (table 1). They had dyspnoea on moderate exertion or at rest (New York Heart Association class III or IV) with dependent oedema, lung congestion on chest $x$ ray, and pleural effusion in some cases. Twenty patients were in sinus rhythm and two had chronic atrial fibrillation. Mean (SD) urinary output in 24 hours was 852 (692) $\mathrm{ml}$. Cardiac failure was caused by ischaemic heart disease in 14 and primary dilated cardiomyopathy in eight. These 16 men and six women gave their written consent to the investigation after being given detailed information on the procedure and its possible clinical benefits. The protocol was approved by the hospital ethics committee.

STUDY DESIGN

After admission, each patient was confined to bed and was treated with his or her usual outpatient doses of frusemide and digoxin by mouth: the doses were kept constant for an individual patient throughout the trial. Angiotensin converting enzyme inhibitors or inotropic drugs other than digitalis were gradually withdrawn during the first 5 days of hospital stay.

Patients were eligible for the study if they had had no exacerbation of symptoms within 2 weeks of hospital admission and ACE inhibitors and inotropic preparations were withdrawn in hospital. Patients whose clinical condition deteriorated for any reason during run-in were immediately withdrawn from the trial.

Ultrafiltration was performed when body weight, renal function, sodium and water excretion, and serum sodium and potassium concentration had remained steady for 4 days. This took about 10 days.
None of these patients was included in our previous studies. ${ }^{11} 192223$ Haemodynamic and hormonal variables and plasma volume were assessed before, immediately after ultrafiltration, and 24 and 48 hours later. Patients were familiarised with the laboratory and its staff; measurements were carried out in an air conditioned room adjacent to the coronary care unit, at $22^{\circ} \mathrm{C}$, after an overnight fast. Tea, coffee, cigarettes and alcohol were not taken in the last 12 hours. Patients had had a stable heart rate, blood pressure, pulmonary artery wedge pressure and cardiac output for at least an hour before the study started. After the baseline measurements were taken the external venous circuit was attached and ultrafiltration was started. Haemodynamic variables were measured every 30 minutes during ultrafiltration and those recorded immediately before and immediately after the procedure were compared. For the next 48 hours the patients remained in bed without any change in treatment. Every 24 hours urine was collected and the haematocrit, serum electrolytes and creatinine, blood urea nitrogen, creatinine clearance, and hormone concentrations were measured.

\section{ULTRAFILTRATION}

We used a D20 SF Amicon diafilter (Danvers, Massachusetts, USA), which allows filtration of plasma water and solutes $<50000 \mathrm{D} .{ }^{11}$ The filter was part of an external circuit, connecting the right femoral vein with an antecubital vein. Flow was driven by a Gambro System (Lund, Sweden) AK peristaltic pump which was set to produce ultrafiltrate at a rate of $500 \mathrm{ml} /$ hour. Veins were cannulated with haemodialysis catheters (Becton Dickinson, Sandy, Utah). Ultrafiltration was continued until the mean right atrial pressure had been reduced to $50 \%$ of baseline or until the hematocrit increased to $50 \%$. The mean volume of fluid removed by this method was $3122 \mathrm{ml}$

Table 1 Demographic and clinical characteristics in 22 patients

\begin{tabular}{|c|c|c|c|c|c|c|c|c|c|c|c|}
\hline \multirow{2}{*}{$\begin{array}{l}\text { Patient } \\
\text { No }\end{array}$} & \multirow{2}{*}{$\begin{array}{l}\text { Age (yr) } \\
\text { and sex }\end{array}$} & \multirow{2}{*}{ Aetiology } & \multirow{2}{*}{$\begin{array}{l}\text { NYHA } \\
\text { class }\end{array}$} & \multicolumn{2}{|c|}{ Clinical data } & \multicolumn{4}{|c|}{ Prior treatment } & \multicolumn{2}{|c|}{ Current treatment (mg/day) } \\
\hline & & & & $P O$ & $P E$ & $D$ & $A C E I$ & $I$ & $L A N$ & $D$ & $F$ \\
\hline $\begin{array}{r}1 \\
2 \\
3 \\
4 \\
5 \\
6 \\
7 \\
8 \\
9 \\
10 \\
11 \\
12 \\
13 \\
14 \\
15 \\
16 \\
17 \\
18 \\
19 \\
20 \\
21 \\
22\end{array}$ & $\begin{array}{l}58 \mathrm{M} \\
64 \mathrm{M} \\
67 \mathrm{~F} \\
77 \mathrm{M} \\
47 \mathrm{M} \\
57 \mathrm{~F} \\
66 \mathrm{M} \\
42 \mathrm{M} \\
51 \mathrm{M} \\
59 \mathrm{M} \\
72 \mathrm{M} \\
64 \mathrm{~F} \\
65 \mathrm{M} \\
65 \mathrm{M} \\
73 \mathrm{~F} \\
62 \mathrm{M} \\
64 \mathrm{M} \\
67 \mathrm{M} \\
79 \mathrm{M} \\
67 \mathrm{~F} \\
48 \mathrm{M} \\
70 \mathrm{~F}\end{array}$ & $\begin{array}{l}\text { CAD } \\
\text { CAD } \\
\text { CAD } \\
\text { IDC } \\
\text { CAD } \\
\text { IDC } \\
\text { CAD } \\
\text { CAD } \\
\text { IDC } \\
\text { IDC } \\
\text { CAD } \\
\text { IDC } \\
\text { CAD } \\
\text { IDC } \\
\text { IDC } \\
\text { CAD } \\
\text { CAD } \\
\text { CAD } \\
\text { IDC } \\
\text { CAD } \\
\text { CAD } \\
\text { CAD }\end{array}$ & $\begin{array}{l}\text { IV } \\
\text { IV } \\
\text { IV } \\
\text { IV } \\
\text { IV } \\
\text { IV } \\
\text { IV } \\
\text { IV } \\
\text { IV } \\
\text { IV } \\
\text { IV } \\
\text { IV } \\
\text { IV } \\
\text { IV } \\
\text { IV } \\
\text { IV } \\
\text { IV } \\
\text { IV } \\
\text { III } \\
\text { III } \\
\text { IV } \\
\text { IV }\end{array}$ & $\begin{array}{l}\text { Yes } \\
\text { Yes } \\
\text { Yes } \\
\text { Yes } \\
\text { Yes } \\
\text { Yes } \\
\text { Yes } \\
\text { Yes } \\
\text { Yes } \\
\text { Yes } \\
\text { Yes } \\
\text { Yes } \\
\text { Yes } \\
\text { Yes } \\
\text { Yes } \\
\text { Yes } \\
\text { Yes } \\
\text { Yes } \\
\text { Yes } \\
\text { Yes } \\
\text { Yes } \\
\text { Yes }\end{array}$ & $\begin{array}{l}\text { Yes } \\
\text { No } \\
\text { No } \\
\text { Yes } \\
\text { No } \\
\text { No } \\
\text { Yes } \\
\text { Yes } \\
\text { No } \\
\text { No } \\
\text { No } \\
\text { Yes } \\
\text { No } \\
\text { No } \\
\text { No } \\
\text { No } \\
\text { No } \\
\text { No } \\
\text { Yes } \\
\text { No } \\
\text { No } \\
\text { No }\end{array}$ & $\begin{array}{l}\text { Yes } \\
\text { Yes } \\
\text { No } \\
\text { Yes } \\
\text { Yes } \\
\text { Yes } \\
\text { Yes } \\
\text { Yes } \\
\text { No } \\
\text { Yes } \\
\text { Yes } \\
\text { Yes } \\
\text { Yes } \\
\text { Yes } \\
\text { No } \\
\text { No } \\
\text { Yes } \\
\text { Yes } \\
\text { Yes } \\
\text { Yes } \\
\text { Yes } \\
\text { Yes }\end{array}$ & 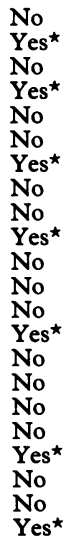 & 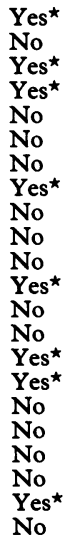 & 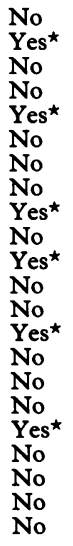 & $\begin{array}{l}0.25 \\
0 \cdot 25 \\
0 \cdot 25 \\
0.125 \\
0 \cdot 25 \\
0.125 \\
0.50 \\
- \\
0 \cdot 125 \\
0 \cdot 125 \\
0.25 \\
0 \cdot 25 \\
0 \cdot 25 \\
- \\
\overline{0} \\
0 \cdot 25 \\
0 \cdot 25 \\
0 \cdot 25 \\
0.25 \\
0 \cdot 125\end{array}$ & $\begin{array}{r}180 \\
160 \\
100 \\
250 \\
100 \\
500 \\
200 \\
140 \\
300 \\
160 \\
500 \\
180 \\
100 \\
160 \\
120 \\
300 \\
120 \\
120 \\
140 \\
160 \\
80 \\
1000\end{array}$ \\
\hline
\end{tabular}

^Stopped 5 days before study.
ACEI, angiotensin-converting enzyme inhibitors; CAD, coronary artery disease; D, digoxin; F, frusemide; IDC, idiopathic dilated cardiomyopathy; I, inotropic preparations; LAN, long acting nitrates; NYHA, New York Heart Association functional class; PO, peripheral oedema; PE, plural effusion. 
(range $1000-5000 \mathrm{ml}$ ). When the procedure was complete the filtering circuit was removed.

\section{HAEMODYNAMIC VARIABLES}

Haemodynamic variables were measured with a number 8 flow directed triple lumen thermodilution catheter introduced percutaneously into a subclavian vein and advanced to the pulmonary artery or to the wedge position. Right atrial pressure was measured at the proximal port of the catheter. A short catheter was introduced into a brachial artery to measure systemic arterial pressure. Pressures were determined with Hewlett Packard (Waltham, Massachusetts) strain gauge transducers (model $1286 \mathrm{~B}$ ) and recorded on a Hewlett Packard 8-channel recorder (model 1064 C). Cardiac output was measured by the thermodilution method with an Edwards (Santa Ana, California) cardiac output computer (9520 A); the mean of three measurements was taken for each time point. Systemic vascular resistance was calculated from the ratio of the driving pressure through the systemic circuit (mean arterial pressure minus mean right atrial pressure) and cardiac output. The driving pressure through the systemic circuit was also used as an index of the renal perfusion pressure. ${ }^{24}$

\section{HUMORAL AND PLASMA VOLUME TESTS}

Measurements of hormones in all samples from a single patient were obtained in the same assay: noradrenaline by high performance liquid chromatography ${ }^{25}$ (Kontron Instruments, Milan, Italy); plasma renin
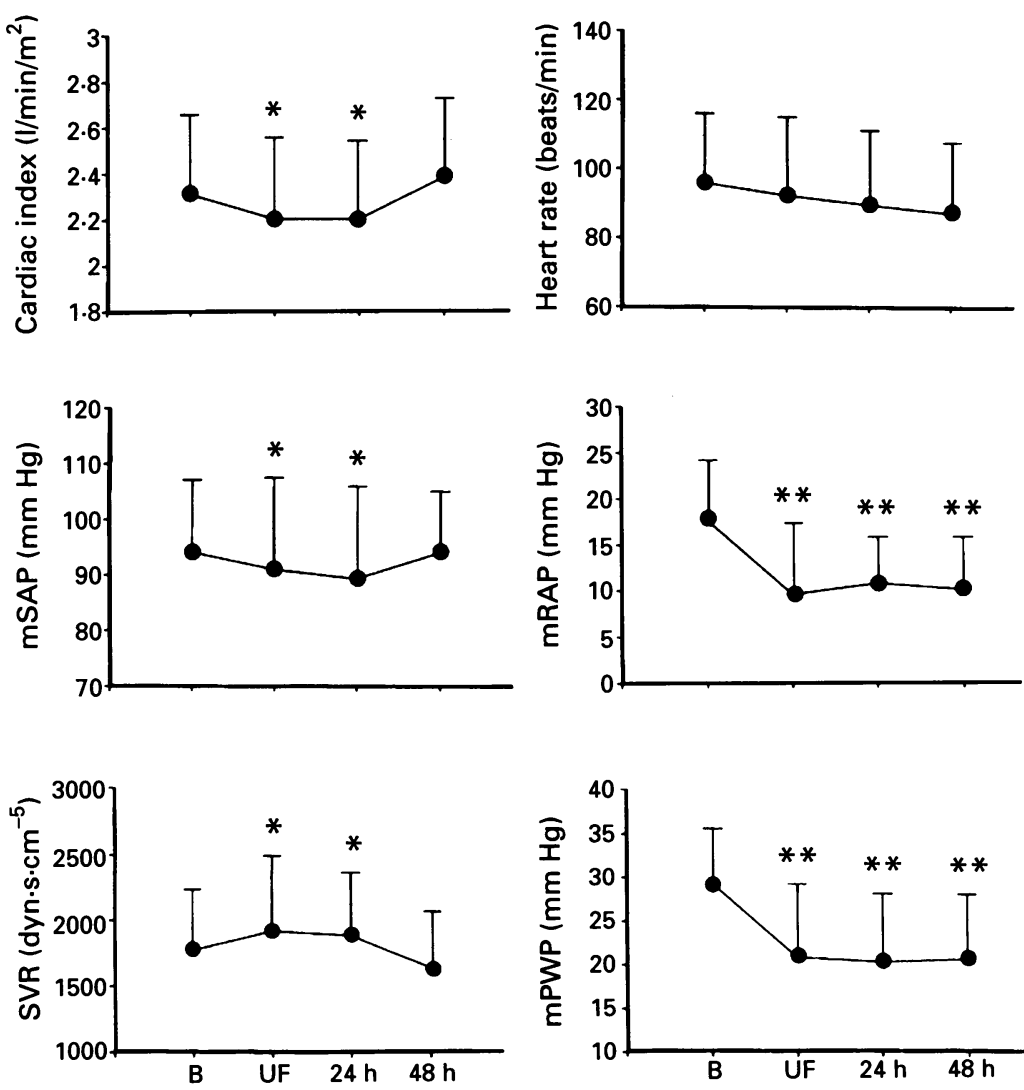

Figure 1 Haemodynamic variables (mean (SD)) before $(B)$, immediately after ultrafiltration (UF), and 24 and 48 hours later. mSAP, mean systemic arterial pressure; $m R A P$, mean right atrial pressure; SVR, systemic vascular resistance; $m P W P$, mean pulmonary wedge pressure. ${ }^{\star} P<0.05 v$ baseline; ${ }^{\star} P<0.01 v$ baseline. activity by radioimmunoassay ${ }^{26}$ (Technogenetics, Milan, Italy), and aldosterone by radioimmunoassay ${ }^{27}$ (Sorin, Saluggio, Italy). We used samples of arterial blood ${ }^{28}$ that were cooled immediately and stored at $-20^{\circ} \mathrm{C}$. The normal plasma values (SD) in the supine position in our laboratory are: noradrenaline $0.911(0.031) \mathrm{nmol} / \mathrm{l}$, aldosterone $2.52(0.7)$ $\mathrm{nmol} / \mathrm{l}$, plasma renin activity $0.029(0.009)$ $\mathrm{nmol} / \mathrm{l} / \mathrm{h}$. The intra-assay variations are $4 \%$, $7 \%$, and $6 \%$ respectively.

Microhaematocrits were determined in triplicate at each period and the percentage changes in plasma volume (PV) were calculated ${ }^{29}$ from the changes in the haematocrit (HCT), according to the following formula:

$\mathrm{PV}_{\mathrm{HCT}}=\frac{100}{(100-\text { HCT pre })} \times \frac{100(\mathrm{HCT} \text { pre }- \text { HCT post })}{\text { HCT post }}$

This method assumes that no erythrocytes have been gained or lost. ${ }^{30}$ Measured haematocrits were corrected for trapped plasma volume and converted to whole body haematocrit. ${ }^{31}$

\section{STATISTICAL ANALYSIS}

Changes from before to after ultrafiltration were assessed by repeated measures of analysis of variance. Analysis of two variable linear regression was used to compare each circulating hormone and selected variables that might have been related to the degree of filling of the arterial compartment: cardiac index, systemic arterial pressure and resistance, plasma volume, and urinary output. We used multiple regression analysis to compare the fluid removed and circulating noradrenaline at baseline with changes in noradrenaline soon after the procedure.

Data are expressed as mean (SD). We regarded a $P$ value of $<0.05$ as significant.

\section{Results}

VALUES AT BASELINE AND AFTER

ULTRAFILTRATION

Haemodynamic variables

The mean cardiac index was $2.351 / \mathrm{min} / \mathrm{m}^{2}$ at baseline, decreased to $2.15 \mathrm{l} / \mathrm{min} / \mathrm{m}^{2}$ (P < $0.05 v$ baseline) soon after filtration and at 24 $h$, and returned to baseline in the next $24 \mathrm{~h}$ (fig 1). Changes in cardiac index were caused by changes in stroke volume; heart rate did not vary significantly from baseline at any time. The corresponding values for mean systemic arterial pressure were 94, 91, 89, $94 \mathrm{~mm} \mathrm{Hg}$; and those for systemic vascular resistance were $1774,1923,1892,1650$ dyn.s.cm ${ }^{-5}$.

Immediately after ultrafiltration mean pulmonary wedge pressure decreased by $29 \%$ and right atrial pressure decreased by $46 \%$. Both variables remained unchanged in the next two days.

Noradrenaline, renin, aldosterone, and plasma volume

At baseline plasma noradrenaline, renin activity, and aldosterone were strikingly raised 

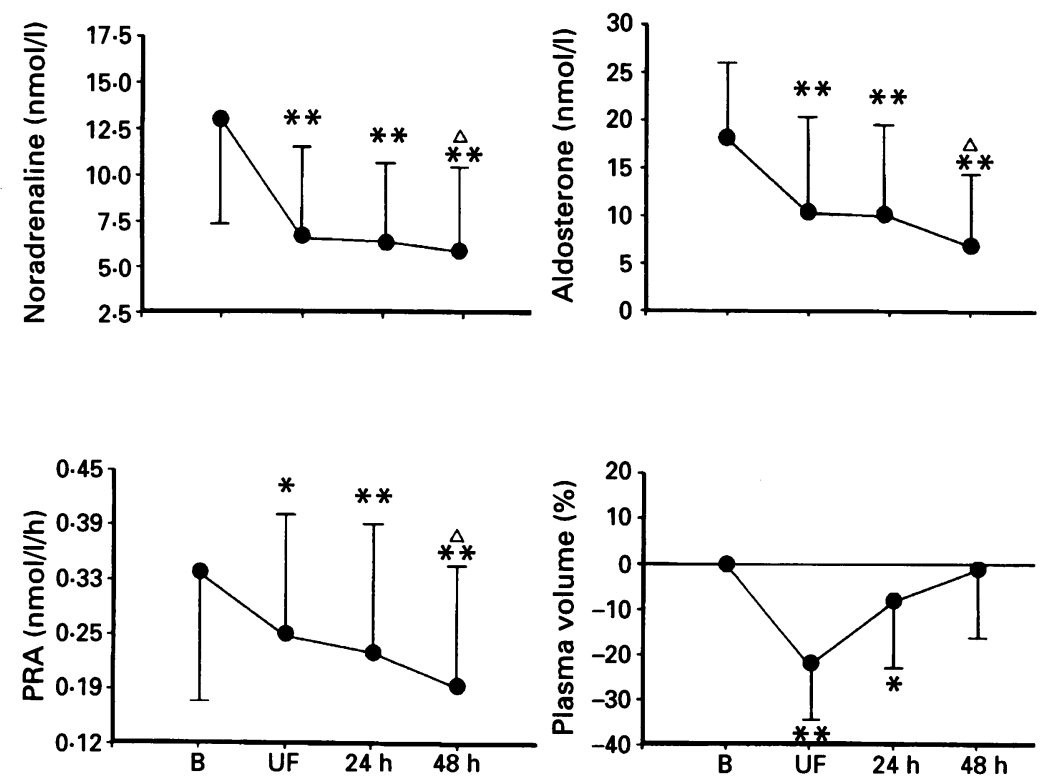

Figure 2 Values (mean (SD)) of circulating noradrenaline, aldosterone, plasma renin activity (PRA), at baseline (B), immediately after ultrafiltration (UF), and 24 and 48 hours later. Mean percentage changes from baseline of plasma volume (PV) at the same intervals are also reported. ${ }^{\star} P<0.05 \mathrm{v}$ baseline; ${ }^{\star * P}<0.01$ v baseline; $\Delta P<0.01 \mathrm{v}$ UF.

Table 2 Sodium and water metabolism and renal function (mean (SD))

\begin{tabular}{|c|c|c|c|c|}
\hline Variable & Baseline & $\begin{array}{l}\text { Immediately } \\
\text { after UF }\end{array}$ & $\begin{array}{l}24 \mathrm{~h} \\
\text { after UF }\end{array}$ & $\begin{array}{l}48 h \\
\text { after UF }\end{array}$ \\
\hline Body weight (kg) & $76(15)$ & $71(14)^{\star \star \star}$ & $71(14)^{\star \star \star}$ & $71(15)^{\star \star \star}$ \\
\hline $\begin{array}{l}\text { Serum sodium concentration } \\
(\mathrm{mmo} / \mathrm{l})\end{array}$ & $139(5)$ & $142(12)$ & $141(5)^{\star \star}$ & $141(3)^{\star \star}$ \\
\hline $\begin{array}{l}\text { Diuresis }(\mathrm{ml} / 24 \mathrm{~h}) \\
\text { Urinary sodium excretion } \\
(\mathrm{mmol} / 24 \mathrm{~h})\end{array}$ & $\begin{array}{l}852(692) \\
39(48)\end{array}$ & & $\begin{array}{c}2132(1181)^{\star \star \star} \\
137(97)^{\star \star \star}\end{array}$ & $\begin{array}{r}1727(753)^{\star \star \star \star} \\
126(103)^{\star \star \star}\end{array}$ \\
\hline $\begin{array}{l}\text { Blood urea }(\mu \mathrm{mol} / \mathrm{l}) \\
\text { Serum creatinine concentration } \\
(\mu \mathrm{mol} / \mathrm{l})\end{array}$ & $\begin{array}{c}52(29) \\
248(177)\end{array}$ & $\begin{array}{r}55(28)^{\star \star \star} \\
265(177)^{\star \star}\end{array}$ & $\begin{aligned} 54(30) \\
239(177)\end{aligned}$ & $\begin{array}{c}49(30)^{\star \star} \\
221(177)^{\star \star}\end{array}$ \\
\hline $\begin{array}{l}\text { Creatinine clearance }(\mathrm{ml} / \mathrm{min}) \\
\text { Renal perfusion pressure } \\
\text { (mm Hg) }\end{array}$ & $\begin{array}{l}19(5) \\
74(26)\end{array}$ & $81(19)^{\star \star}$ & $\begin{array}{l}46 \cdot 3(13)^{\star \star} \\
78(16)^{\star}\end{array}$ & $\begin{array}{l}44 \cdot 2(6)^{\star \star \star} \\
78(15)^{\star \star}\end{array}$ \\
\hline Ultrafiltrate (ml) & & $3122(1199)$ & & \\
\hline
\end{tabular}

UF, extracorporeal ultrafiltration; ${ }^{\star} \mathrm{P}<0.05 ; \star \star \mathrm{P}<0.01$;

$\star \star \star P<0.001 v$ baseline.

(fig 2). Ultrafiltration elicited an immediate significant fall of each of them by 52,28 , and $46 \%$ of baseline, respectively. In the next two days we recorded a further significant decrease in these variables. Plasma volume was reduced by $22 \%$ immediately after the procedure and by $10 \% 24$ hours later; it fully recovered in the next 24 hours.

Sodium and water metabolism and renal function Mean baseline $24 \mathrm{~h}$ urinary output was 852 (692) $\mathrm{ml}$ and mean body weight was $76 \mathrm{~kg}$ (table 2). The day after ultrafiltration (mean $3122 \mathrm{ml}$ of plasma water) diuresis increased by $150 \%$ and urinary sodium excretion by $251 \%$ of baseline, body weight decreased by $5.1 \mathrm{~kg}$, creatinine clearance increased by $142 \%$ and serum sodium, urea nitrogen, and creatinine concentrations were unchanged. At 48 hours diuresis and output of sodium were $102 \%$ and $233 \%$ respectively higher than at baseline; body weight was $5 \mathrm{~kg}$ less; creatinine clearance was $131 \%$ higher; urea nitrogen and creatinine concentrations were $6 \%$ and $10 \%$ lower, respectively. Renal perfusion pressure was $9 \%$ higher soon after ultrafiltration and $6 \%$ higher in the two subsequent 24 hour periods.

Correlations with noradrenaline, renin, and aldosterone

We correlated hormone values at baseline with each other and with the corresponding values for other selected variables that may be related to filling of the arterial compartment ${ }^{4}$ : cardiac index, mean systemic arterial pressure, systemic vascular resistance, plasma volume, urinary output (table 3 ). Noradrenaline and renin were positively related to each other but not to aldosterone, cardiac index, arterial pressure and systemic vascular resistance; noradrenaline and renin were inversely related to urinary output. Twenty four hours after ultrafiltration the changes in noradrenaline

Table 3 Correlations of baseline (BL) hormone values and their variations 24 hours after ultrafiltration $\Delta 24 \mathrm{~h}$ ) with each other and with corresponding values of other selected variables that may be involved in the regulation of filling of the arterial compartment.

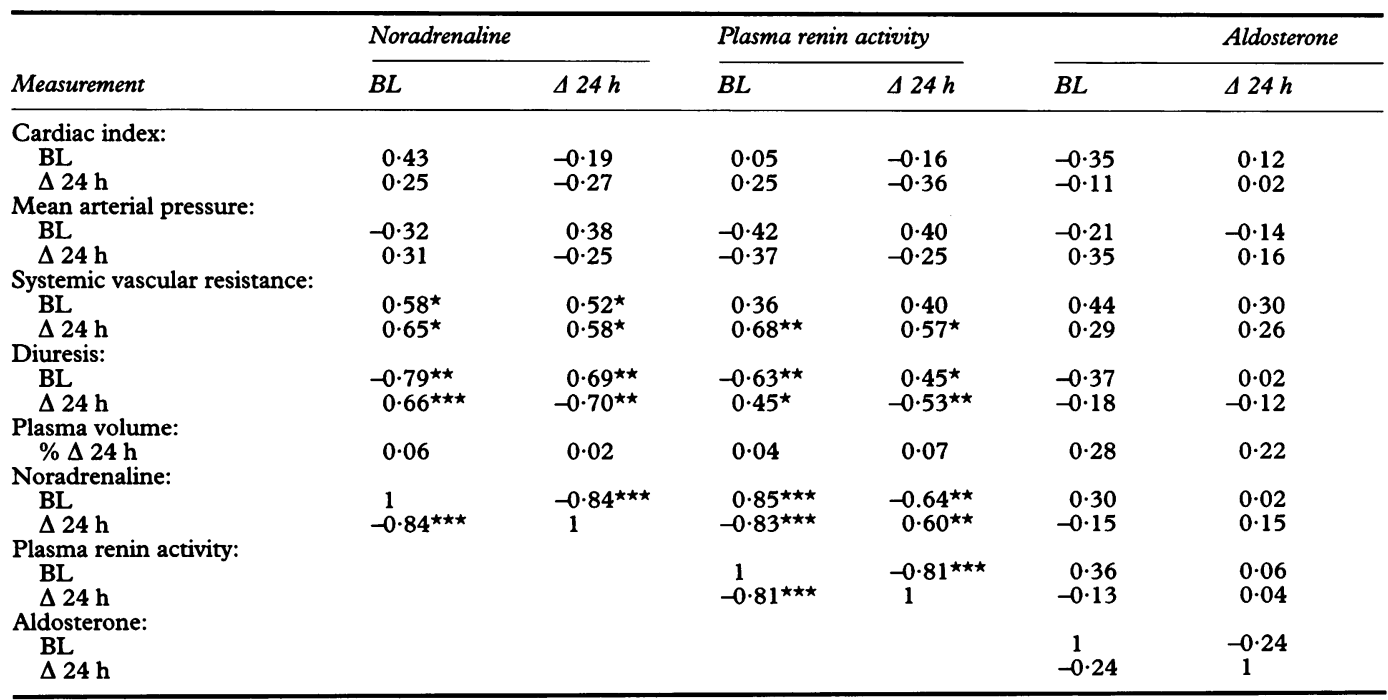

Correlation coefficients were obtained by linear regression analysis:

${ }^{\star} \mathrm{P}<0.05 ;{ }^{\star \star \mathrm{P}}<0.01 ;{ }^{\star \star \star} \mathrm{P}<0.001$ 
and renin were related to each other and to changes in systemic vascular resistance and urinary output; they were not related to changes in aldosterone, cardiac index, arterial pressure, and plasma volume. Changes of plasma volume did not correlate with the amount of fluid withdrawn. There was a positive significant correlation $(P<0.001)$ between changes in plasma noradrenaline with ultrafiltration and the combination of the amount of fluid removed and the circulating concentration of noradrenaline at baseline.

\section{Discussion}

Patients in this study had accumulation of fluid associated with striking activation of the neurohumoral axis. In these patients water and salt retention and hormonal stimulation greatly exceeded the limits of a homoeostatic response. ${ }^{7}$

Ultrafiltration removed a mean volume of $3122 \mathrm{ml}$ of plasma water at a rate of $500 \mathrm{ml} / \mathrm{h}$. This loss of fluid, which equals or exceeds in quantity the entire normal plasma water compartment, must have been offset by entry of fluid from the interstitial space. In other studies removal of $3 \mathrm{~kg}$ of fluid during regular haemodialysis led to a sharp $20 \%$ decrease in plasma volume. ${ }^{3233}$ We obtained similar results as judged by the haematocrit method; the only blood loss in our patients was the small amount taken for hormone determinations. The complexity of the interactions among the variables (magnitude and direction of osmotically active solutes and oncotically active proteins, age, and capillary and venous hydrostatic pressures) affecting intravascular volume balance ${ }^{30}$ may explain why changes in plasma volume were unrelated to the amount of ultrafiltrate.

Decreased plasma volume, right atrial pressure, cardiac index, and mean arterial pressure and raised systemic vascular resistance immediately after ultrafiltration were consistent with some degree of intravascular volume deprivation. The circulating volume was probably restored in the next 48 hours, as shown by recovery of cardiac index, plasma volume, and blood pressure. Paradoxically, during this interval we found that water and sodium excretion were enhanced and the neurohumoral axis was further depressed. It is reasonable to ask whether reducing pressure volume by $20 \%$, right atrial pressure to 10 $\mathrm{mm} \mathrm{Hg}$, and mean arterial pressure to $90 \mathrm{~mm}$ $\mathrm{Hg}$ is sufficient to provoke neuroendocrine activation. It is significant, however, that the response was exactly the opposite of a classic defence reaction to volume depletion. This may suggest that at this stage of the disease the defence mechanisms were exhausted or that factors other than hypovolaemia were maintaining water retention and neurohumoral overactivity.

Baseline noradrenaline and renin concentrations correlated with each other, as expected from the feedback loops linking the renin system with the adrenergic nervous system and noradrenaline. ${ }^{34-36}$ The correlation of their changes after ultrafiltration with each other suggests that the interrelation of the two variables persisted after body fluid was reduced. A tentative interpretation is that renin helped to modulate aldosterone secretion and that noradrenaline facilitated the release of renin. Noradrenaline may be viewed as the initiator of the hormonal adjustments to withdrawal of fluid. The mechanisms that cause circulating concentrations of noradrenaline to decrease with ultrafiltration are probably manifold and not easily explored. The combination of the volume of ultrafiltrate removed and the baseline concentration of noradrenaline correlated with changes in the circulating catecholamine soon after the procedure. It is possible that noradrenaline was filtered from the blood and the concentration decreased because extracellular fluid entered the circulating compartment. This interpretation, however, does not accord with the increase in plasma noradrenaline after ultrafiltration in patients with congestive heart failure and without water retention, ${ }^{19}$ or with the continuing decrease in noradrenaline concentration that occurred in the two days after ultrafiltration in our patients. Other mechanisms are reactivation of reflex inhibitory stimuli originating from periphery, heart (greater ventricular shortening ${ }^{37}$ caused by reduction in diastolic volume and pressure and wall tension), or lungs ${ }^{38}$ (resolution of lung congestion) and modulation of baroreceptor sensitivity, sympathetic activity, and secretion of renin and aldosterone by effects on atrial natriuretic peptides or arginine vasopressin. ${ }^{46-41}$ However, the lack of association between plasma concentrations of noradrenaline and cardiovascular function is not consistent with these interpretations. In fact, in these patients who had a fifteenfold higher concentration of circulating noradrenaline than normal a reduction of more than $50 \%$ did not have important circulatory consequences. A similar decrease of sympathetic firing would probably produce very different effects. At this stage of the disease more of the neurotransmitter seems to accumulate than is needed for receptor activity. ${ }^{39}$

The lungs and kidneys play a fundamental role in removing noradrenaline from the blood. Relief of lung congestion improves fractional extraction. ${ }^{42}$ Outflow of the neurotransmitter from the kidneys accounts for nearly $25 \%$ of the total spillover to plasma in healthy subjects and the kidneys extract $35-55 \%{ }^{42}$ In congestive heart failure congestion and hypoperfusion of the kidneys are largely responsible for raising noradrenaline. In dogs clearance of noradrenaline depends on blood flow and a severe reduction of flow results in a spillover of noradrenaline from the kidneys. ${ }^{42}$ We did not measure renal plasma flow; none the less, the increased output of urine, sodium excretion, creatinine clearance, and renal perfusion pressure after fluid withdrawal were consistent with improved renal haemodynamics and enhanced sodium concentration in the macula densa. These changes probably increased the clearance of 
noradrenaline and reduced the release of renin and aldosterone.

We suggest that in patients with water retention in heart failure, withdrawal of intravascular fluid by ultrafiltration and the consequent reabsorption of a corresponding amount from the extravascular space, reduces the concentrations of circulating hormones by various mechanisms and increases the output of water and sodium by the kidneys. This in turn, as shown by a strong correlation between the increase in diuresis and decrease in hormone concentrations, further decreases hormones in the blood. Removal of fluid by ultrafiltration may interrupt a positive feedback loop between salt and water retention and activation of the neurohumoral axis.

It is unlikely that vascular underfilling perpetuates the stimulation of the neurohumoral axis and accumulation of fluid at all stages of congestive heart failure. In more advanced stages organs such as the kidneys and lungs may play a fundamental part in keeping circulating concentrations of hormones high; the positive feedback loop between fluid and salt retention and the humoral axis seems to be a mechanism responsible for progression of congestive heart failure.

1 Bernard C. Leçons sur les phénomènes de la vie commun aux animaux et aux vététaux. Isted, vol 1. Paris: JB Bailliere et Fils, 1878; 18

2 Kuchel GA, Avorn J, Reed MJ, Fields D. Cardiovascula responses to phlebotomy and sitting in middle-aged and elderly subjects. Arch Intern Med 1992;152:366-70.

3 Kim KE, Onesti G, Moyer JH, Swartz C. Ethacrinic acid and furosemide. Diuretic and hemodynamic effects and clinical uses. Am $\mathcal{f}$ Cardiol 1971;27:407-15.

4 Schrier RW. Body fluid regulation in health and disease: a unifying hypothesis. Ann Intern Med 1990;113:155-9.

5 Francis GS, Goldsmith SR, Olivari MT, Levine TB, Cohn $\mathrm{J}$. The neurohumoral axis in congestive heart failure. Ann Intern Med 1984;101:370-7.

6 Packer M. Neurohormonal interactions and adaptations in congestive heart failure. Circulation 1988;77:721-30.

7 Remes J, Tikkanen I, Fyhrguist F, Pyörälä K. Neuroendocrine activity in untreated heart failure. Circulation 1988;77:721-30

8 Peters JP. The role of sodium in the production of edema. N Engl f Med 1948;239:353-62.

9 Smith HW. Salt and water volume receptors: an exercise in physiologic apologetics. $A m$ f Med 1957;23:623-52.

10 Lauer AL, Saccaggi A, Ronco C, Belledonne M, Glabman $\mathrm{S}$, Bosch JP. Continuous arteriovenous hemofiltration in the critically ill patient. Clinical use and operation charthe critically ill patient. Clinical use and ope

11 Rimondini A, Cipolla CM, Della Bella P, Grazi S, Sisillo E, Susini G, Guazzi MD. Hemofiltration as short-term E, Susini G, Guazzi MD. Hemofiltration as short-term treatment for refract

12 Simpson IA, Rae AP, Gribben J, Boulton Jones JM Allison MEM, Hutton I. Ultrafiltration in the management of refractory congestive heart failure. Br Heart 1986;55:344-7.

13 Cleland JGF. Ancillary therapy for heart failure. Curr Opin Cardiol 1991:65:249-55.

14 Bhatia ML, Singh I, Manchanda SC, Khanna PK, Roy SB. Effect of furosemide on pulmonary blood volume. SB. Effect of furosemide

15 Kram H, Chan W, Espiner EA, Nicholls MG Haemodynamic and hormone responses to acute and chronic furosemide therapy in congestive heart failure. Clin Sci 1980;59:443-9.

16 Francis GF, Siegel RM, Goldsmith SR, Olivari MT, Levine TB, Cohn JN. Acute vasoconstrictor response to intravenous furosemide in patients with chronic congestive heart failure. Activation of the neurohumoral axis. Ann Intern Med 1985;103:1-6.
17 Richardson A, Scriven AJ, Poole Wilson PA, Bayliss J, Parameshwar J, Sutton GC. Double-blind comparison of captopril alone against frusemide plus amiloride in mild heart failure. Lancet 1987;ii:709-11.

18 Cleland JGF, Gillen G, Dargie HJ. The effects of frusemide and angiotensin-converting enzyme inhibitors and their combination on cardiac and renal haemody namics in heart failure. Eur Heart $\mathcal{F}$ 1988;9:132-41.

19 Marenzi GC, Grazi S, Giraldi F, Lauri GF, Perego GB Guazzi M, et al. Interrelation of humoral factors, hemodynamics and fluid and salt metabolism in congestive heart failure: effects of extracorporeal ultrafiltration. $A m \mathcal{F}$ Med 1993;94:49-56.

20 Zimmerman BG, Gusslen J. Pattern of renal vasoconstriction and transmitter release during sympathetic stimulation in the presence of angiotensin and cocaine. tion in the presence of angiotens

21 Guazzi MD, Ellsworth OT, Freis ED. Influence of the adrenergic system in renovascular hypertension. adrenergic system in re
Cardiovasc Res $1971 ; 5: 71-80$.

22 Cipolla CM, Grazi S, Rimondini A, Susini G, Guazzi M, Della Bella P, Guazzi MD. Changes in circulating norepinephrine with hemofiltration in advanced congestive heart failure. Am $\mathcal{F}$ Cardiol 1990;66:987-94.

23 Agostoni PG, Marenzi GC, Pepi M, Doria E, Salvioni A, Perego G, et al. Isolated ultrafiltration in moderate congestive heart failure. $7 \mathrm{Am}$ Coll Cardiol 1993;21:424-431.

24 Packer M, Lee WH, Kessler PD. Preservation of glomerular filtration rate in human heart failure by activation of ar filtration rate in human heart failure by activation of the renin-

25 Guazzi MD, Alimento M, Fiorentini C, Pepi M, Polese A. Hypersensitivity of lung vessels to catecholamines in systemic hypertension. Br Med $\mathcal{F}$ 1986;293:291-4.

26 Guazzi MD, Fiorentini C, Olivari MT, Bartorelli A Magrini F, Biancardi C. Circulatory and renin responses in man to unilateral reduction of the renal perfusion pressure. Cardiovasc Res 1981;15:637-42.

27 Walsh PR, Wang MC, Gitterman ML. A simplified radioimmunoassay for plasma aldosterone. Ann Clin Lab Sci 1981;11:138-45.

28 Levine TB, Francis GS, Goldsmith SR, Simon AB, Cohn JN. Activity of the sympathetic nervous system and renin angiotensin system assessed by plasma hormone levels and their relationship to hemodynamic abnormalities in and their relationship to ham 7 Cardiol 1982;49:1659-66.

29 Van Stone JC, Bauer J, Carey J. Effect of dialysate sodium concentration on body fluid compartment volume concentration on body fluid compartment volume
plasma renin activity and plasma aldosterone concentration in chronic hemodialysis patients. Am $\mathcal{F}$ Kidney $D i$ 1982;2:58-64.

30 Kirschbaum B. Comparison of indirect methods to estimate plasma volume changes during hemodialysis. Int Artif Organs 1988;5:307-13.

31 Van Beaumont W, Strand JC, Petrofsky JS, Hipskind SG, Greenleaf JE. Changes in total plasma content of electrolytes and proteins with maximal exercise. $\mathcal{f} A p p l$ Physiol 1973;34:102-6.

32 Basile C, Coates JE, Ulan RA. Plasma volume changes induced by hypertonic hemofiltration and standard hemodialysis. Am ₹ Nephrol 1987;7:264-9.

33 Di Maggio A, Basile C, Scatizzi A. Plasma volume changes induced by sequential ultrafiltration-hemodialysis and sequential hemodialysis-ultrafiltration. Int $\mathcal{f}$ Artif Organ 1987;10:291-4.

34 Davies JO, Freeman RH. Mechanisms regulating renin release. Physiol Rev 1976;56:1-56.

35 Johns EJ. Role of angiotensin II and the sympathetic nervous system in the control of renal function. F Hypertens 1989;7:691-701.

36 Licht MR, Izzo JL. Humoral effects of norepinephrine on renin release in humans. Am 7 Hypertens 1989;2:788-91.

37 Abboud FM. Role of cardiac afferent nerves in regulation of circulation during coronary occlusion and heart failure. In: Abboud FM, Fozzard HA, Gilmore JP, Reis DJ, eds. In: Abboud FM, Fozzard HA, Gilmore JP, Reis DJ, eds. Disturbances in neurogenic control of the

38 Guazzi M, Libretti A, Zanchetti A. Tonic reflex regulation of the cat's blood pressure through vagal afferents from the cardiopulmonary region. Circulation Res 1962;11: $7-16$.

39 Franciosa JA, Schwartz DE. Acute hemodynamic effects of norepinephrine inhibition in patients with severe chronic congestive heart failure. $f \mathrm{Am}$ Coll Cardiol 1989;14: 624-30.

40 Laragh $\mathrm{JH}$. Atrial natriuretic hormone, the reninangiotensin axis, and blood pressure-electrolyte homeoangitis $N$ Engl $₹$ Med 1985:313:1330-40.

41 Munzel T, Drexler H, Holtz J, Kurtz S, Just $H$ Mechanisms involved in the response to prolonged infusion of atrial natriuretic factor in patients with chronic heart failure. Circulation 1991;83:191-201.

42 Esler M Lambert G. Assessment of human sympathetic nervous system activity from measurements of norepinephrine turnover. Hypertension 1988;11:3-20. 